05.1

\title{
Влияние локальной коррозии на динамику деформационных полос и разрушение алюминий-магниевого сплава
}

\author{
(ㄱ А.А. Шибков, М.Ф. Гасанов, Р.Ю. Кольцов, А.А. Денисов \\ Тамбовский государственный университет им. Г.Р. Державина, Тамбов, Россия \\ E-mail: shibkov@tsu.tmb.ru
}

Поступило в Редакцию 8 апреля 2019г.

В окончательной редакции 24 апреля 2019 г.

Принято к публикации 24 апреля 2019г.

\begin{abstract}
Влияние локальной коррозии на динамику полос макролокализованной деформации и разрушение алюминий-магниевого сплава АМг6 исследовано методом высокоскоростной видеосъемки поверхности деформируемого образца. Установлено, что коррозионное пятно, вызванное локальным воздействием гидроксида натрия на поверхность сплава, является аттрактором деформационных полос, взаимодействие которых приводит к преждевременному разрушению и сокращению ресурса пластичности сплава.
\end{abstract}

Ключевые слова: локальная коррозия, алюминий-магниевый сплав, механические свойства, локализация пластической деформации, трещина.

DOI: 10.21883/PJTF.2019.15.48077.17828

Многие высокотехнологичные алюминиевые сплавы проявляют механическую неустойчивость, которая выражается в явлении прерывистого течения, известном как эффект Портевена-Ле Шателье (ПЛШ). Этот эффект связан со спонтанным формированием зон макролокализованной деформации - деформационных полос, которые негативно влияют на качество поверхности промышленных изделий, ухудшают формуемость сплавов, ускоряют коррозию и могут вызывать внезапное разрушение [1-4]. Взаимосвязь полосообразования и коррозии промышленных алюминиевых сплавов представляет собой малоисследованную проблему физики прочности, пластичности и разрушения. В настоящей работе экспериментально исследуется влияние локальной коррозии на зарождение деформационных полос, их пространственно-временну́ю структуру и развитие магистральной трещины в алюминий-магниевом сплаве АМг6, применяемом в авиакосмической технике, автомобильной промышленности и химическом машиностроении.

Поликристаллические образцы сплава АМг6 (Al-6.15 wt.\% Mg-0.65 wt.\% Mn-0.25 wt.\% Si-0.21 wt.\% Fe) в форме двухсторонних лопаток с размерами рабочей части $6 \times 3 \times 0.5 \mathrm{~mm}$ вырезались из листового проката после холодной прокатки (степень обжатия 0.3). Образцы предварительно отжигались в течение часа при температуре $450^{\circ} \mathrm{C}$ и закаливались на воздухе. После термообработки средний размер зерна составил около $10 \mu \mathrm{m}$. В качестве корродирующей среды использовался $50 \%$ раствор гидроксида натрия. Щелочная среда вызывает разрушение защитной оксидной пленки $\mathrm{Al}_{2} \mathrm{O}_{3}$ и ускоряет коррозионный процесс в соответствии с реакцией [5]:

$$
\mathrm{Al}+\mathrm{NaOH}+\mathrm{H}_{2} \mathrm{O} \rightarrow \mathrm{NaAlO}_{2}+(3 / 2) \mathrm{H}_{2}
$$

Перед механическими испытаниями на поверхность образца в области размером около $1 \mathrm{~mm}$ наносилась капля раствора $\mathrm{NaOH}$. После высыхания капли образцы растягивались в разрывной машине Instron (модель 3344) со скоростью $\dot{\varepsilon}_{0}=3 \cdot 10^{-3} \mathrm{~s}^{-1}$ до разрушения. Оптический мониторинг пространственно-временны́х структур полос локализованной деформации проводился с помощью высокоскоростной цифровой видеокамеры Photron (FASTCAM Mini UX50/100). Для контрастирования изображений использовалась компьютерная программа вычитания последовательных цифровых изображений [6].

На рис. 1 представлены кривые растяжения образца с коррозионным пятном (кривая 1) и образца, не подвергавшегося коррозионному воздействию (кривая 2). Оба образца демонстрируют эффект ПЛШ - повторяющиеся скачки напряжения со средней амплитудой около $10 \mathrm{MPa}$. Наличие коррозионного пятна с площадью, составляющей около $2 \%$ от площади поверхности рабочей части образца, уменьшает деформацию до разрушения на 16\%. Для исследования механизма уменьшения пластичности проводилась видеосъемка (со скоростью $500 \mathrm{fps}$ ) поверхности образцов с целью выявления роли пространственно-временни́х структур деформационных полос в локализации разрушения на коррозионном пятне.

Фрагмент эволюции деформационных полос, которая завершается разрывом образца, представлен на рис. 2 . Первичная полоса обычно распространяется в направлении, проходящем через коррозионное пятно. Она зарождается на участке между границей коррозионного пятна и ребром плоского образца (кадр 5). Угол наклона полосы деформации относительно оси растяжения, составляющий 55-63, соответствует направлению максимальных касательных напряжений (для изотропного 


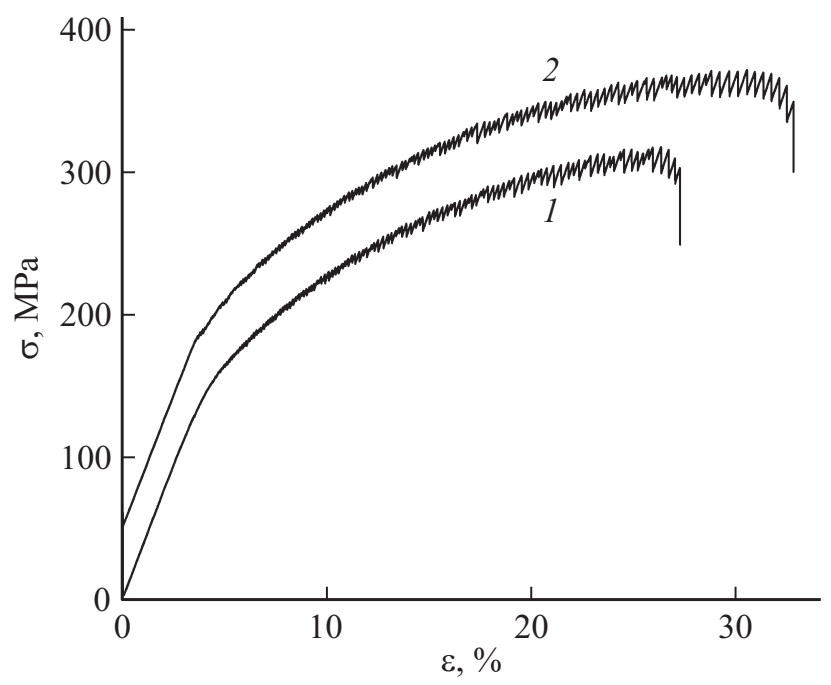

Рис. 1. Кривые растяжения образцов сплава АМг6: 1 - образца с коррозионным пятном диаметром около $1 \mathrm{~mm}$, 2 - образца без коррозионного пятна (исходного). Скорость растяжения $\dot{\varepsilon}_{0}=3 \cdot 10^{-3} \mathrm{~s}^{-1} . T=300 \mathrm{~K}$. Кривые смещены по оси напряжения на $50 \mathrm{MPa}$.

пластически деформируемого плоского образца он составляет $55^{\circ} 44^{\prime}$ [7]). Поэтому в полосе локализованной деформации преобладает сдвиговая мода пластической деформации.

Для исследования статистики полос деформации, прошедших через будушую поверхность разрушения, рабочая часть образца размером $6 \times 3 \mathrm{~mm}$ условно разделялась на 50 эквидистантных параллельных сечений, подсчитывалось количество границ полос $\Delta N$, пересекающих каждое сечение $x=x_{i}$ (где $i=1$, $2, \ldots, 50-$ номер сечения), и строилась гистограмма $n_{i}\left(x_{i}\right)=\Delta N\left(x_{i}\right) / N$, где $N$ - общее количество границ полос. На рис. 3 представлена типичная гистограмма $n_{i}\left(x_{i}\right)$, характеризующая пространственное статистическое распределение полос деформации в образце с коррозионным пятном. Анализ гистограммы полос показывает следующее: 1) магистральная трещина всегда проходит через сечение образца, наиболее интенсивно „обработанное“ деформационными полосами, т.е. позиция трещины всегда совпадает с резким максимумом гистограммы $\left.n_{i}\left(x_{i}\right) ; 2\right)$ максимум гистограммы полос и соответственно магистральная трещина находятся в области коррозионного пятна (рис. 3).

Отметим, что в плоских образцах деформационные полосы представляют собой шейки двух типов: полосы, пересекающие под углом $\varphi \approx 55-60^{\circ}$ к оси растяжения узкую грань образца, а под прямым углом - широкую грань (тип 1), и полосы, пересекающие под углом $\varphi$ к оси растяжения широкую грань, а под прямым углом - узкую (тип 2) [8]. Видеосъемка показывает, что непосредственно перед разрушением, за $130-150 \mathrm{~ms}$ до разрыва образца с коррозионным пятном, деформационные полосы типа 2 изменяют угол $55-60^{\circ}$ на со- пряженный $110-120^{\circ}$ относительно оси растяжения при неподвижном „центре тяжести“ полосы, совпадающем с центром коррозионного пятна (рис. 2, кадры 5 и 13).

Формирование полосы деформации, как известно, связано с динамикой дислокационного ансамбля с избытком дислокаций одного механического знака („механического заряда“) [6]. В условиях одноосного растяжения появление механического заряда создает в материале дальнодействующие напряжения изгиба, которые релаксируют за счет спонтанного зарождения сопряженной полосы с противоположным углом наклона относительно оси растяжения. Такое поведение деформационных полос аналогично рассмотренному в [9] динамическому процессу пересечения двух макрополос локализованного сдвига по схеме креста на стадии образования шейки перед разрывом образца сплава, не демонстрирующего эффект ПЛШ. Из анализа самосогласованных сдвигов в этих макрополосах следует, что равнодействующая сдвиговых напряжений в полосах дает нормальное напряжение растяжения в области пересечения полос, которое может привести к зарождению микротрещины нормального отрыва как начальной стадии разрушения материала [9].

Из данных видеосъемки следует, что на дне коррозионного пятна в области пересечения полос типа 2
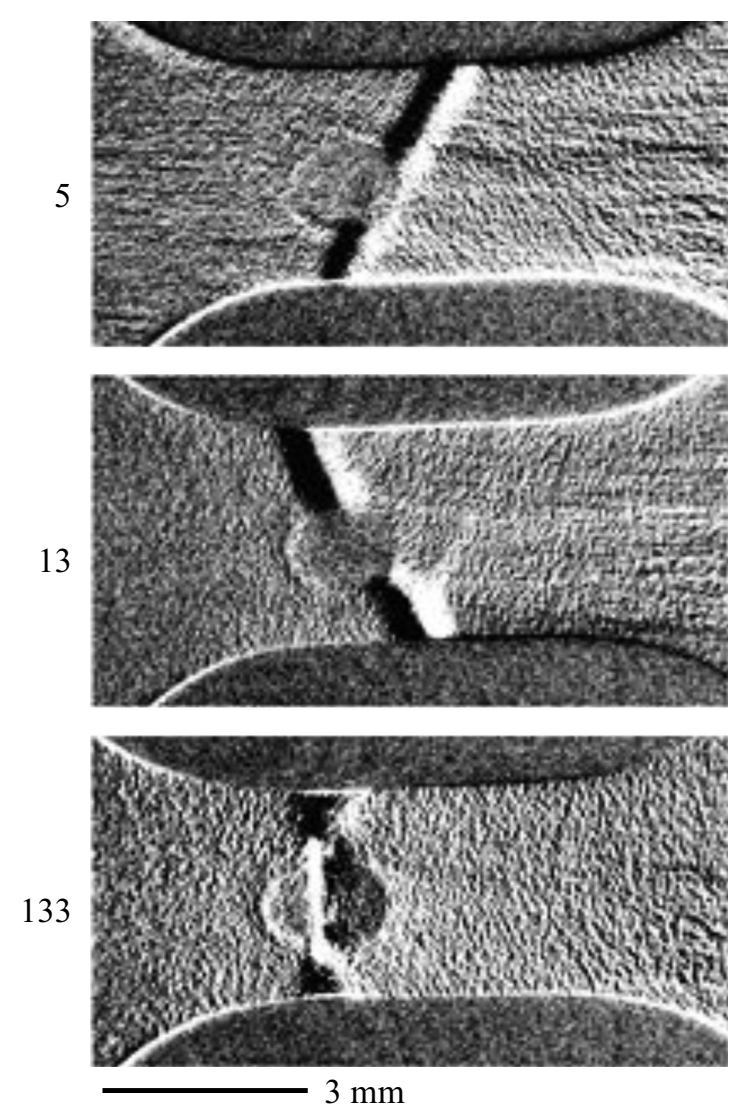

Рис. 2. Результаты компьютерной обработки фрагмента видеофильма эволюции деформационных полос в сплаве АМг6 с коррозионным пятном. Скорость видеосъемки $500 \mathrm{fps}$. Числа — номера кадров. 


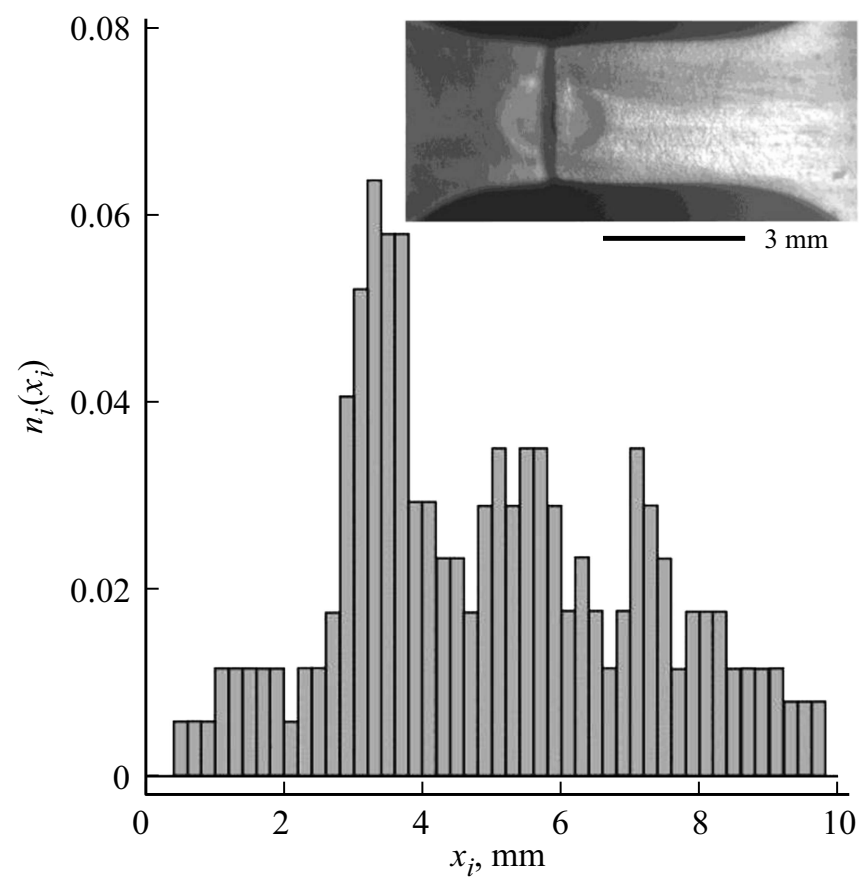

Рис. 3. Гистограмма полос в образце с коррозионным пятном. На вставке - кадр видеофильма через $2 \mathrm{~ms}$ после разрыва образца.

формируется деформационная полоса типа 1 (рис. 2, кадр 133). Магистральная трещина зарождается в центре коррозионного пятна на границе этой полосы. На границе деформационной полосы, как известно [10], возникают внутренние напряжения, связанные с высоким градиентом деформационного поля в области неоднородной деформации между пластически деформируемым и недеформируемым материалом, где аккомодационные напряжения несовместности максимальны. В этой области преимущественно и возникают микротрещины, способные развиться в магистральную трещину.

В работе [4] на примере алюминий-магниевого сплава, содержащего $3 \% \mathrm{Mg}$, установлено, что основной причиной разрушения металла, демонстрирующего эффект ПЛШ, является потеря подвижности деформационных полос ПЛШ вследствие деформационного упрочнения, вызванного ростом плотности дислокаций. Резкое падение скорости полосы, формирование статической сопряженной полосы для компенсации изгибающего момента происходит, как показано в [4], по достижении деформации Консиде́ре и связано с началом образования шейки. Таким образом, формирование статических сопряженных полос, образующих крестообразную структуру, характерно для стадии образования шейки перед разрывом образцов металлических сплавов, демонстрирующих и не демонстрирующих эффект ПЛШ.

Коррозионное пятно на поверхности сплава АМг6, как следует из данных видеосъемки, является областью наиболее вероятного формирования статических сопряженных деформационных полос, которые и приводят к преждевременному образованию шейки и разрыву образца. В отличие от роста общей плотности дислокаций как основной причины потери подвижности полос в сплаве, не подвергавшемся коррозии, множественные концентраторы напряжения в области коррозионного пятна, связанные с разрывами оксидной пленки $\mathrm{Al}_{2} \mathrm{O}_{3}$, микрорастрескиванием поверхностного слоя, являются основной причиной локализации статических деформационных полос в области коррозионного пятна. Это свидетельствует о ключевой роли состояния корродирующей поверхности в развитии макроскопической пластической неустойчивости материала, демонстрирующего эффект ПЛШ.

Разрушению пластичных материалов, как известно, всегда предшествует локализация пластической деформации. В случае алюминиевого сплава с коррозионным пятном перед макроскопическим разрушением образца происходит цепочка процессов локализации деструктивных процессов на различных масштабных уровнях: 1) локализация деформационных полос коррозионным пятном; 2) локализация микроразрушения на границах включений вторичной $\beta\left(\mathrm{Al}_{3} \mathrm{Mg}_{2}\right)$-фазы вследствие динамического взаимодействия с включениями активных деформационных полос; 3) зарождение магистральной трещины на границе деформационной полосы. Естественно, что при такой цепочке процессов локализации пластической деформации и разрушения магистральная трещина пройдет по коррозионному пятну.

Таким образом, на основе прямых in situ экспериментов в работе выявлен механизм разрушения алюминиймагниевого сплава с коррозионным пятном, состоящий в том, что коррозионное пятно является поверхностным концентратором напряжения, локализующим деформационные полосы ПЛШ - предвестники макроскопического разрушения сплава. Локализация полос в сечении, проходящем через коррозионное пятно, и, следовательно, резкая потеря их подвижности приводят к преждевременному старту магистральной трещины, которая зарождается и распространяется по границе неподвижной деформационной полосы.

Основные результаты работы состоят в следующем.

1. С помощью метода высокоскоростной видеосъемки установлено, что коррозионное пятно является аттрактором деформационных полос, которые зарождаются преимущественно в сечениях образца, проходящих через коррозионное пятно. Это приводит к формированию в области пятна четкого максимума на гистограмме полос.

2. Магистральная трещина распространяется в сечении образца, соответствующем максимуму гистограммы полос на границе последней деформационной полосы, где возникают избыточные напряжения несовместности, и представляет собой трещину поперечного сдвига.

3. Микроскопический механизм разрушения, как предполагается, связан с образованием микротрещин, а затем пор вблизи включений — частиц вторичной 
$\beta\left(\mathrm{Al}_{3} \mathrm{Mg}_{2}\right)$-фазы - в результате взаимодействия с этими включениями активных полос деформации.

Выявленный механизм разрушения, связанный с макролокализацией пластической деформации на коррозионном пятне в сплаве, демонстрирующем эффект ПЛШ, является важным дополнением к электрохимическим механизмам, обычно используемым для объяснения коррозионного разрушения металлов [11]. Полученные результаты могут быть использованы для оценки прочности, пластичности и долговечности промышленных алюминиевых сплавов, эксплуатируемых в условиях действия механических нагрузок и агрессивной среды.

\section{Финансирование работы}

Исследования влияния агрессивной среды на механические свойства алюминий-магниевого сплава выполнены при поддержке Российского научного фонда (проект № 17-79-10404), высокоскоростные оптические исследования влияния коррозионного пятна на динамику и статистику деформационных полос проведены при поддержке Российского научного фонда (проект № 18-19-00304) с использованием оборудования ЦКП ТГУ им. Г.Р. Державина.

\section{Конфликт интересов}

Авторы заявляют, что у них нет конфликта интересов.

\section{Список литературы}

[1] Antonovich S.D., Armstrong R.W. // Prog. Mater. Sci. 2014. V. 59. P. 1-160.

[2] Klusemann B., Fischer G., Bohlke Th., Svendsen B. // Int. J. Plast. 2015. V. 67. P. 192-216.

[3] Cai Y.L., Yang S.L., Wang Y.H., Fu S.H., Zhang Q.C. // Mater. Sci. Eng. A. 2016. V. 664. P. 155-164.

[4] Yuzbekova D., Mogucheva A., Zhemchuzhnikova D., Lebedkina T., Lebyodkin M., Kaibyshev R. // Int. J. Plast. 2017. V. 96. P. 210-226.

[5] Бык М.В. // Защита металлов. 2004. Т. 40. № 3. С. 321-324.

[6] Шибков А.А., Золотов А.Е., Михлик Д.В., Желтов М.А., Шуклинов А.В. // Деформация и разрушение материалов. 2009. № 9. C. 22-29.

[7] Работнов Ю.Н. Механика деформируемого твердого тела. М.: Наука, 1988. С. 524.

[8] Шибков А.А., Золотов А.Е., Желтов М.А., Денисов А.А., Гасанов М.Ф., Кочегаров С.С. // ЖТФ. 2016. Т. 86. В. 5. C. $68-76$.

[9] Деревягина Л.С., Панин В.Е., Гордиенко А.И. // Физ. мезомеханика. 2007. Т. 10. № 4. С. 59-72.

[10] Hahner P., Ziegenbein A., Rizzi E., Neuhauser H. // Phys. Rev. B. 2002. V. 65. N 13. P. 134109.

[11] Ангал Р. Коррозия и защита от коррозии. Долгопрудный: Интеллект, 2014. 334 c. 